\title{
BRONCHIAL MUCUS AS A COMPLEX FLUID: MOLECULAR INTERACTIONS AND INFLUENCE OF NANOSTRUCTURED PARTICLES ON RHEOLOGICAL AND TRANSPORT PROPERTIES
}

\author{
Marcin Odziomek*, Martyna Kalinowska, Aleksandra Płuzińska, Antoni Rożeń, \\ Tomasz R. Sosnowski
}

Warsaw University of Technology, Faculty of Chemical and Process Engineering, ul. Waryńskiego 1, 00-645 Warsaw, Poland

\section{Dedicated to Prof. Leon Gradoń on the occasion of his 70th birthday}

\begin{abstract}
Transport properties of bronchial mucus are investigated by two-stage experimental approach focused on: (a) rheological properties and (b) mass transfer rate through the stagnant layer of solutions of mucus components (mucine, DNA, proteins) and simulated multi-component mucus. Studies were done using thermostated horizontal diffusion cells with sodium cromoglycate and carminic acid as transferred solutes. Rheological properties of tested liquids was studied by a rotational viscometer and a cone-plate rheometer (dynamic method). First part of the studies demonstrated that inter-molecular interactions in these complex liquids influence both rheological and permeability characteristics. Transfer rate is governed not only by mucus composition and concentration but also by hydrophobic/hydrophilic properties of transported molecules. Second part was focused on the properties of such a layer in presence of selected nanostructured particles (different nanoclays and graphene oxide) which may be present in lungs after inhalation. It was shown that most of such particles increase visco-elasticity of the mucus and reduce the rate of mass transfer of model drugs. Measured effects may have adverse impact on health, since they will reduce mucociliary clearance in vivo and slow down drug penetration to the bronchial epithelium during inhalation therapy.
\end{abstract}

Keywords: mucus, biopolymers, interactions, diffusion, rheology, nanostructured particles

\section{INTRODUCTION}

Understanding of transport phenomena of small molecules in polymer and biopolymer solutions has a considerable practical value in many areas. In medicine, the pharmacokinetics of drugs administrated by inhalation or gastrointestinal route highly depends on their transport rate through the mucus layer covering the surface of epithelium. In the respiratory tract the mucus forms a protective layer against pathogens and pollutants inhaled with air (Cone, 2009). Foreign particles deposited on the mucus surface are removed from the respiratory tract by means of two mechanisms: mucociliary clearance (i.e. transport due to flow of the mucus induced by beating of the cilia) and cough, both being dependent on mucus composition which determines its rheological properties. If viscosity is too low, gravitational forces will overcome the mucociliary transport, so the mucus can seep down to the lungs which favors bacterial growth and increases the risk of infections. A similar risk occurs when too viscous mucus hinders cilia activity and their beating becomes ineffective. It can be observed in pulmonary diseases which are also associated with the increased thickness of mucus layer, e.g. cystic fibrosis (Rubin, 2009). Bronchial mucus is a non-Newtonian fluid with viscoelastic and thixotropic properties. 
Appropriate degree of elasticity is necessary for efficient transmission of energy from moving cilia to the liquid with minimal dissipation (Cone, 2009), therefore abnormal elasticity of this secretion has adverse impact on respiratory defense/protective mechanisms. Proper functioning of the second defense mechanism, i.e. cough clearance, is strictly related to thixotropy of the mucus, i.e. to time-dependent changes in mucus rheology after imposing high shear rates generated by forceful air flow during coughing. The shearing stresses result both in temporal and permanent changes of the mucus internal structure and - consequently - its rheological properties (Lai et al. 2009).

The strongest influence on mucus structure is imposed by mucins, which are high-molecular-weight glycoproteins, capable of forming physically entangled gel structures by cross-linking. The degree of entanglements depends mainly on the molecular weight of mucin subunits (which is in the range of 0.5-40 MDa), and mucin concentration, which typically does not exceed $5 \% \mathrm{w} / \mathrm{w}$, but may significantly increase during a disease. According to King (2005), a common mucin molecule with the molecular weight of 2-3 MDa is randomly coiled in aqueous medium, forming a 400-600 nm sphere. At $1 \%(\mathrm{w} / \mathrm{w})$ concentration, centers of mucin molecules are separated by a distance of 70-75 $\mathrm{nm}$. Hence, mucins at physiologic concentration exist as highly interpenetrating polymer coils, and the main form of crosslinking is through dynamic intermolecular entanglements (King, 2005). Except for that, mucins present also a multitude of potential non-covalent (electrostatic, hydrophobic, hydrogen, van der Waals) interaction sites for binding themselves but also with other molecules and particles present in the liquid. In the mucus, mucins are present in a slightly basic (pH 7.4) aqueous environment which contains small amounts (up to $1 \% \mathrm{w} / \mathrm{w} /$ ) of ions $\left(\mathrm{Na}^{+}, \mathrm{K}^{+}, \mathrm{Ca}^{2+}\right.$ and $\left.\mathrm{Cl}^{-}\right)$and macromolecules like proteins (approximately 1\% w/w), DNA (approximately $0.02-1.5 \% \mathrm{w} / \mathrm{w}$ ) and lipids (approximately $1-2 \% \mathrm{w} / \mathrm{w}$ ) (Lai et al., 2009). Due to mutual interactions, all these components have their input to rheological properties of mucus.

As an example, most of the lipid content is associated with hydrophobic domains of mucin glycoproteins. On the other hand, hydrophobic amino acids of the free proteins are frequently bound to the molecule's interior, whereas polar (hydrophilic) amino acids are bound outwards, allowing dipoledipole interactions with the solvent (Cone, 2009). Components of mucus are also responsible for specific interactions with foreign particles or molecules which can appear in the mucus. Such interactions are often of van der Waals type which are low-affinity bonds with short half-lives, often broken within milliseconds due to thermal energy, although their multitude makes their cumulative effect be significant (Cone, 2009; Woodley, 2001).

In summary, mucus ensures protection of the organism by a few different ways due to composition, structure and rheology. Mucus is a steric barrier (Muhr and Blanshard, 1982), and its continuous secretion requires that surface of underlying epithelium may be reached by arriving molecules or particles (e.g. drugs) only after their migration against an outward current. The polymeric network physically obstructs the mass transfer through this liquid layer. The crosslink density of this network depends mainly on the length of mucin subunits, as mucin molecules are bound together by covalent disulphide bonds between the cysteine-rich, carboxyl- and amino- terminal sites of the protein backbone. Crosslink density in mucin solutions can be decreased by mucolytics (e.g. N-acetylcystine: NAC) which reduce di-sulphur bonds between mucin molecules, lowering the effective viscosity of these solutions and facilitating the diffusive mass transfer. It was demonstrated that NAC at concentration of $1.5 \%(\mathrm{w} / \mathrm{w})$ lowered the apparent viscosity of dense mucus (mucin concentrations: $20 \% \mathrm{w} / \mathrm{w}$, which reflects a pulmonary disease) by more than $40 \%$, simultaneously increasing diffusion rate of small molecules by 2.2-fold (Odziomek et al. 2012; Odziomek et al., 2015). Such increase of mucus permeability can be explained by shortening the diffusion path in the complex gel-like liquid structure (Muhr and Blanshard, 1982).

The current paper is focused on the basic analysis of transport properties of the bronchial mucus and it was divided into two parts. The first part investigates the influence of main mucus components on the apparent viscosity and the mass transfer rate of selected low-molecular weight substances (acting as a 
model of inhalable drugs). Obtained data are discussed on the basis of inter-molecular interactions providing the way of evaluating the role of each component in mucus rheology and permeability.

The second part of the paper extends the experimental studies to the influence of selected nanostructured particles, NPs - which may be present in bronchial fluid after inhalation - on rheological properties and permeability of the bronchial mucus simulant. These issues are of special importance for understanding the physicochemical reasons of health effects caused by inhaled nanoparticulate air contaminants. It is well known that such particles easily penetrate the respiratory tract and deposit on the lung surface (Marijnissen and Gradoń, 2010; Sosnowski, 2015; Yang et al., 2008). It was also demonstrated that NPs are capable (in a material- and dose-dependent manner) of modifying physicochemical properties of lung surfactant which is present in the alveolar region of lungs (Kondej and Sosnowski, 2013; Sosnowski et al., 2011). Similarly, it may be expected that NPs interaction with the affect natural mass transport processes in the bronchial tree: the clearance but also penetration of drugs administered by inhalation. The aim of this research is to identify the physical phenomena responsible for these effects.

\section{MATERIALS AND METHODS}

\subsection{Structure of the experimental studies}

As mentioned above, the studies were divided into two parts. Part I investigates transport properties in solutions of individual mucus constituents by viscometry and analysis of the diffusive mass transfer of two low-molecular mass solutes. Part II which is focused on effects caused by nanostructured particles on transport properties of artificial mucus. It involves more sophisticated rheological analysis of the mucus in presence of NPs and the measurements of diffusive transport. The data regarding experiments done in both parts is presented in Table 1.

Table 1. Types of experiments done within the study. Materials and experimental methods are characterized in the subsequent sections.

\begin{tabular}{|l|c|c|c|c|}
\hline $\begin{array}{c}\text { Type of experiment } \rightarrow \\
\text { Sample type } \downarrow\end{array}$ & $\begin{array}{c}\text { Viscometry } \\
\text { at constant } \\
\text { shear rate }\end{array}$ & $\begin{array}{c}\text { Mass transfer } \\
\text { in horizontal } \\
\text { diffusion cell } \\
\text { (HDC) }\end{array}$ & $\begin{array}{c}\text { Concentration } \\
\text { measurements } \\
\text { method }\end{array}$ & $\begin{array}{c}\text { Dynamic } \\
\text { rheological } \\
\text { characteristics }\end{array}$ \\
\hline \multicolumn{2}{|c|}{ Part I - measurements done for solutions of individual mucus components } \\
\hline ALB-water $(15 \mathrm{mg} / \mathrm{ml})$ & + & + & Spectrophotometry & - \\
\hline DNA- water $(15 \mathrm{mg} / \mathrm{ml})$ & + & + & Spectrophotometry & - \\
\hline MUC-water $(15 \mathrm{mg} / \mathrm{ml})$ & + & + & Spectrophotometry & - \\
\hline $\begin{array}{l}\text { ALB+DNA+MUC } \\
(15+15+15 \mathrm{mg} / \mathrm{ml})\end{array}$ & + & + & Spectrophotometry & - \\
\hline \multicolumn{2}{|c|}{ Part II - measurements done for mucin solutions in presence of NPs } \\
\hline $\begin{array}{l}\text { MUC + water } \\
(50 \mathrm{mg} / \mathrm{ml})+(200 \mathrm{mg} / \mathrm{ml})\end{array}$ & - & + & HPLC & + \\
\hline MUC + water + BT & - & + & HPLC & + \\
\hline MUC + water + MM & - & + & HPLC & + \\
\hline MUC + water + GOx & - & + & HPLC & + \\
\hline
\end{tabular}

ALB - albumin, MUC - mucin, BT - bentonite NPs, MM - hydrophobic montmorillonite, NPs, GOx graphene oxide NPs. 


\subsection{Materials}

Mucin - MUC (type II, M2378), albumin - ALB (A5253), deoxyribonucleic acid - DNA (74782), trizma base (T4661), carminic acid - CA (29253) were purchased from Sigma Aldrich, phosphate buffer and sodium azide were purchased from POCH (Poland). Disodium cromoglycate (DC) was donated by GlaxoSmithKline Pharmaceuticals S.A. (Poland). Nanostructured particles of bentonite BT $\left(\mathrm{H}_{2} \mathrm{Al}_{2} \mathrm{O}_{6} \mathrm{Si}\right)$ and hydrophobized montmorillonite - MM (I.28E), were purchased from SigmaAldrich. These NPs were characterized in detail in the paper by (Kondej and Sosnowski, 2013) where they were denoted as PGV and MM1 particles. Graphene oxide (GOx) nanoparticles were fabricated in Graphene Laboratory at the Faculty of Chemical and Process Engineering, Warsaw University of Technology. Water used for the preparation of all solutions and for other analytical purposes were obtained from the reverse osmosis purification system (Puricom, USA).

\subsection{Sample preparation}

Liquid samples used for rheological and mass transfer studies were prepared by dissolution of mucin, albumin, DNA in phosphate buffer ( $\mathrm{pH}$ 7.4) to achieve the desired final concentration $(15 \mathrm{mg} / \mathrm{ml})$. Overall concentration of dissolved substances in the sample imitating the natural mucus (MUC + ALB + DNA) was equal to $45 \mathrm{mg} / \mathrm{ml}$. The concentration of mucin in samples used for studies with NPs (Part II of the study) was $50 \mathrm{mg} / \mathrm{ml}$ and $200 \mathrm{mg} / \mathrm{ml}$, whereas the ratio of NPs to MUC was 1:50 and 1:20, respectively. NPs were first dispersed in phosphate buffer using ultrasounds. Then mucin was added gradually to the gently stirred solutions. The $\mathrm{pH}$ of all prepared samples was precisely controlled and, if necessary, adjusted with trizma base. A small amount $(0.02 \% \mathrm{w} / \mathrm{w})$ of sodium azide was added to protect the samples from microbial contamination. After setting the $\mathrm{pH}$ and adding all components, mucus samples were gently stirred for the time necessary for them to complete dissolution.

\subsection{Rheological measurements}

The apparent viscosity of samples containing different mucus components (Part I of the study) was measured with rotational rheometer (Smart - Fungilab, Spain). In this case, for a straightforward comparison of the results, all measurements were done at the similar shear rate $\gamma^{\cdot} \approx 8 \mathrm{~s}^{-1}$, which lies within the range found in bronchial mucus at normal physiological conditions (Cone, 2009). All viscosity measurements were taken at constant temperature $\left(20 \pm 0.5^{\circ} \mathrm{C}\right)$. In Part II of the studies, which were done for mucin solutions in presence of NPs, more extensive rheological measurements were conducted with Anton Paar Rheometer (model MCR 302, Austria), working with cone and plate geometry and Peltier temperature controller. The applied dynamic oscillatory shear measurements are suited for studies of complex liquids since they do not rupture the internal structure of the fluid (Schramm, 2000). Tested liquid is subjected only to small oscillations of fixed amplitude (strain) at different shear frequencies (Lai et al., 2009). These measurements were done at physiological temperature $\left(37 \pm 0.2^{\circ} \mathrm{C}\right)$.

\subsection{Mass transfer studies}

Permeability of tested solutions (Part I) or suspensions (Part II) was measured out using thermostated glass horizontal diffusion cells, HDC (PermeGear, Germany) as described in detail elsewhere (Odziomek et al., 2015). In brief, the donor and receiver compartments of HDC were filled with $5 \mathrm{ml}$ of the aqueous solution of diffusing substance (DC or CA, $0.1 \mathrm{mg} / \mathrm{ml}$ ) and pure phosphate buffer ( $\mathrm{pH} 7.4$ ), respectively. Liquids in both compartments were agitated by a magnetic microstirrer in order to assure 
uniform concentration and to reduce the local mass transfer resistance at the surface of the supporting membranes. The $3-\mathrm{mm}$ stagnant layer $(300 \mu \mathrm{l})$ of the tested liquid was placed between the compartments, and it was supported from both sides by PVDF (polyvinyl difluoride) Durapore ${ }^{\circledR}$ porous membranes (pore size $0.1 \mu \mathrm{m}$, thickness $0.125 \mathrm{~mm}$ - Millipore, USA). The membranes, which were selected according to literature data (Norris and Sinko 1996), guarantee low intrinsic resistance for diffusing solutes, and they simultaneously assure no leakage of the inner sample. Diffusion cells were thermostated $\left(20 \pm 0.5^{\circ} \mathrm{C}\right.$ in Part I, and $37 \pm 0.5^{\circ} \mathrm{C}$ in Part II). Concentration of diffusing substances in each compartment was periodically measured either by UV-VIS spectrophotometry (Thermo Scientific, USA - in Part I of the studies), or by HPLC (model Infinity 1220, Agilent Technologies, USA, equipped with UV-VIS detector and $100 \mathrm{~mm}$ ZORBAX Eclipse Plus C18 column - in Part II of the studies). DC and CA were analyzed at $325 \mathrm{~nm}$ and $540 \mathrm{~nm}$ wavelength, respectively. During each experiment (typically: 6 hours) samples from each compartment were taken for analysis at 30 min intervals $(25 \mu \mathrm{l}$ for HPLC or $0.5 \mathrm{ml}$ for spectrophometry - these samples were returned to the compartments after quick absorbance reading).

The effective diffusion coefficient in the stagnant layer, $D_{\text {eff, }}$, was calculated from the appropriate solution of the Fick's law, assuming the steady-state process in the layer (Desai and Vadgama, 1992; Odziomek et al., 2015). This assumption is true when the time necessary for solute transport through the layer, $t_{d}$, is significantly shorter than the time necessary to change its concentration in the HDC compartments, $t_{\mathrm{c}}$. It is correct only if the volume of the stagnant layer is significantly smaller than cell volume (Truskey et al., 2009), which is true for our system $(0.3 \mathrm{vs.} 5 \mathrm{ml})$. It was also assumed that the main resistance of the mass transfer from donor phase to acceptor phase is located in the stagnant layer. It means that membrane resistance is negligible and the mass transfer resistance at the membrane surface in both diffusion chambers is eliminated by stirring inside each cell. Another simplification is the assumption of constant concentration difference between both diffusion chambers. As the measurements were conducted in a closed system, the concentration of analyzed substances in both diffusion chambers would equalize at sufficiently long time. However, because of limited time of measurement (6 hours), the solute concentration in the donor chamber was always much higher than that in the acceptor chamber which justifies the above assumption (Brodin et al., 2010).

\section{RESULTS AND DISCUSSION}

\subsection{Part I - influence of individual mucus constituents on transport properties}

The first part of the study was focused on determination of the permeability (i.e. effective diffusivity: $D_{\text {eff, }}$ for DC and CA) and the apparent viscosity (measured at the fixed shear rate: $\mu_{a}$ ) of aqueous systems which contained different components of the mucus: albumin, DNA, mucin (each at concentration of $15 \mathrm{mg} / \mathrm{ml}$ ). Comparison of $D_{\text {eff }}$ for DC and CA is shown in Fig. 1.

As expected, mass transfer of DC and CA through a 3-mm liquid layer in HDC is fastest in water $\left(D_{\text {eff }}=8.35 \cdot 10^{-10} \mathrm{~m}^{2} / \mathrm{s}\right.$ for DC and $9.24 \cdot 10^{-10} \mathrm{~m}^{2} / \mathrm{s}$ for CA). Presence of any mucus constituents noticeably reduces diffusive transport through the layer. For both transported compounds (DC and CA), the effective diffusion coefficient is reduced by $17 \%-25 \%$ in ALB or DNA solutions, by approximately $30 \%$ in MUC solution, and by more than $40 \%$ in the reconstituted mucus containing a mixture of all three constituents (MIX $=$ MUC+ALB+DNA).

Measured apparent viscosity $\mu_{a}$ of ALB or DNA solutions was similar and almost twice higher than that of water (1.79-1.85 mPa s). Mucin solution was more viscous (2.64 $\mathrm{mPa} \mathrm{s})$, and the highest $\mu_{a}$ was found for MIX ( $5 \mathrm{mPas}$ ), although in this system the total content of the components was also higher $(45 \mathrm{mg} / \mathrm{ml})$. It can be stated therefore, that liquid viscosity somehow correlates with the permeability of 
the stagnant layer. However, a more detailed explanation of the mass transfer in these complex fluids can be derived from further analysis of molecular interactions presented herewith.

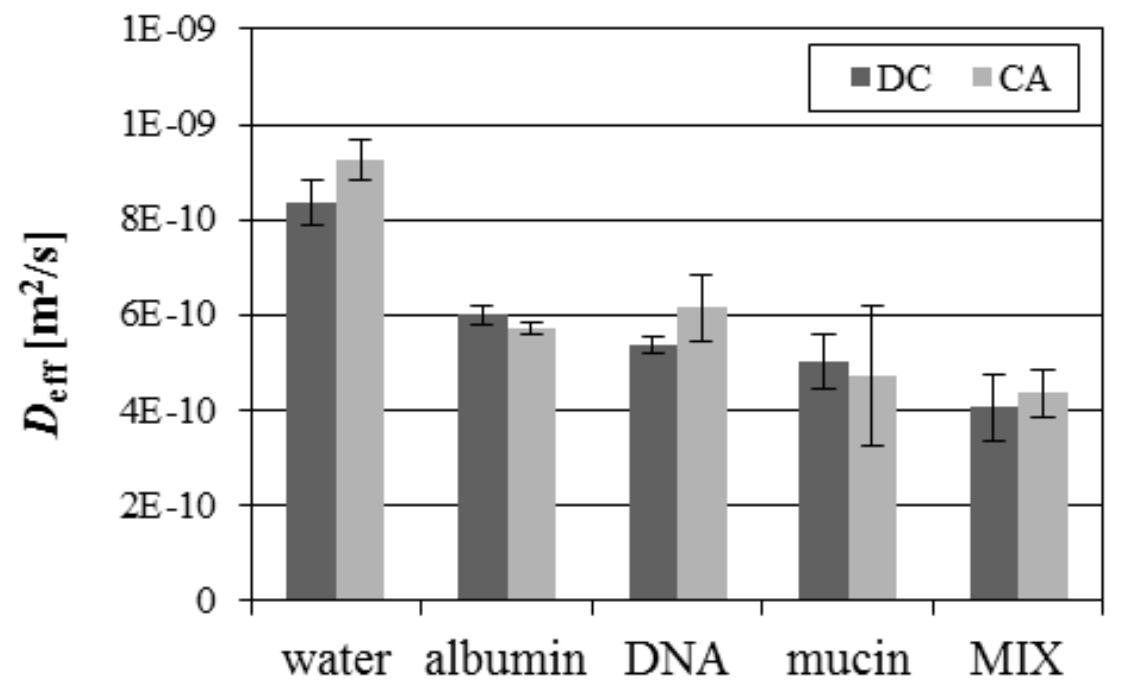

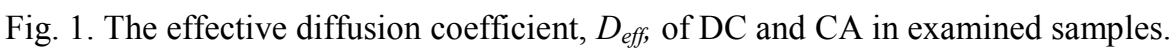
Average $\pm \mathrm{SD}$, number of replicates $=3$

Insignificant differences in mass transfer rate, which were found for both studied compounds (DC and CA) of similar molecular mass (468.4 Da and $492.4 \mathrm{Da}$, respectively) may be explained by their different physiochemical properties. DC has a more hydrophilic character as suggested by partition coefficient $(\log P=-4.80)$ which refers to the equilibrium of the compound (in the ionized and unionized form) between aqueous and organic phases at physiological $\mathrm{pH}$. For carminic acid, $\log P=1.53$ which means that $\mathrm{CA}$ molecules are more hydrophobic. This explains the minor differences in their transport rate through the complex liquids tested in this work.

It is known that MUC - as biopolymer - allows to create a spatial network by crosslinking through intermolecular entanglements, although smaller molecules such as ALB or DNA do not demonstrate sufficient interactions. As a consequence, transport of solutes cannot be hindered for ALB or DNA by 'obstruction effect', but it is possibly reduced by specific interactions between diffusing molecules and the components of the solution. For all forms of DNA, the global structure has an overall negative charge and the total electrostatic potential is negative. This is largely due to the phosphate groups of DNA which bear an overall negative charge due to the negatively charged oxygen atoms they have. However, DNA has both positive and negative charges covering its outer structure (Rohs et al., 2010) which may be responsible for stronger interactions of DNA molecules with more polar molecules of DC. This explains slightly slower diffusion of DC as compared to CA through DNA solution.

The difference also might be expected for DC and CA transport in ALB solution. In solutions of globular proteins (like albumin), hydrophobic amino acids are frequently bound to the molecule's interior whereas polar hydrophilic amino acids are bound outwards, allowing dipole-dipole interactions with the solvent (Cone, 2009). Such a structure should result in greater hindering of DC molecules (more hydropophilic) than CA molecules (more hydrophobic). However, results presented in Fig. 2 show practically no difference in the rate of diffusive mass transport of both solutes, which may suggest that such interactions are not critical for mass transfer rate under tested conditions.

For MUC, the reduction of transport rate can be explained by mucin's structure. Protein backbone of mucin has PTS regions - regions with high content of amino acids like proline, threonine and serine (Cone, 2009). Hydroxyl groups of these amino acids are bound through O-glycosylation linkages with carbohydrate molecules which are partly responsible for expansion of the mucus gel. This is the result of the negative charge of sialic acid $(\mathrm{pKa} \sim 2.6)$ which is bound to these side chains. Generally, 
oligosaccharide side chains of mucins are responsible for electrostatic interactions and non-specific hydrogen bonding, while the protein backbone allows for hydrophobic interactions. Such a structure allows them to bind substances with different properties, and therefore to hinder their transport rate through the gel (Bansil and Turner, 2006; Bhat et al., 1995; Sanders et al., 2000; Widdicombe, 1997).

The lowest values of $D_{\text {eff }}$ were obtained for DC $\left(4.04 \times 10^{-10} \mathrm{~m}^{2} / \mathrm{s}\right)$ and CA $\left(4.35 \times 10^{-10} \mathrm{~m}^{2} / \mathrm{s}\right)$ in the sample MIX which mimics natural bronchial mucus. These results can be explained by 'obstruction effect' in the liquid mixture with high (although physiologically-relevant) total concentration of dissolved substances. These findings also demonstrate good barrier properties of the mucus layer in protecting tracheobronchial tree and the whole organism against penetration of inhaled particles.

Presented results show that due to varied display of interaction modes, the mucus is well adapted to trap molecules that have either hydrophobic or hydrophilic properties. In Part II of this paper, we do the next step in this analysis by identifying interactions of mucin with nanostructured particles.

\subsection{Part II. Influence of nanostructure particles (NPs) on transport properties of mucin solutions}

Investigations focused on relations between NPs and rheological and transport properties of mucin solutions were done for two MUC concentrations: 50 and $200 \mathrm{mg} / \mathrm{ml}$. The lower concentration value lies within physiological range for bronchial mucus, which can be expected only at conditions of a lung disease (Boucher, 1988). For 'physiological' concentration, the content of NPs was adjusted to $1 \mathrm{mg} / \mathrm{ml}$ $(\mathrm{NPs} /$ mucin $=1: 50)$, while for the 'disaese' - to $10 \mathrm{mg} / \mathrm{ml}(\mathrm{NPs} /$ mucin $=1: 20)$. NP concentration of $1 \mathrm{mg} / \mathrm{ml}$ corresponds to the deposited dose which may be expected after a few-hour breathing with air contaminated by NP dust (Kondej and Sosnowski, 2013). The higher NPs concentration $(10 \mathrm{mg} / \mathrm{ml})$ was chosen to test the sensitivity of the already impaired system ('disease') to dust overloading, which is known to occur in occupational or accidental exposures (Oberdörster, 1995).

The rheological measurements have been carried out with strain amplitude 3\% which kept the system inside linear viscoelasticity region. Concentrated MUC samples show both an elastic and viscous response when subjected to sinusoidal strain. The storage $\left(G^{\prime}\right)$ and loss $\left(G^{\prime \prime}\right)$ moduli of each sample for angular frequency range $\omega=0.1-100 \mathrm{rad} /$ each are shown in Fig. 2. The values of phase shift angles: $\phi$ $=\arctan \left(G^{\prime \prime} / G^{\prime}\right)$, measured at strain amplitude 3\%, are compared in Fig. 3.

Loss modulus $G$ "' is higher in the whole range of angular frequencies for solutions with pure MUC and MUC + bentonite NPs. For the other two samples (with MM and GOx) the viscous component ( $G$ ') of the dynamic response exceeds the elastic component (storage modulus $G^{\prime}$ ) only at low frequencies. In this range both samples react more like a viscous liquid than elastic solid. It can be understood as dashpot-like response of their internal structure which gives enough time to react to a given strain (i.e. to relax). At high frequencies the relation between $G$ ' and $G$ '' is reversed, so both samples react more like solids ('spring') since there is not sufficient time for the 'dashpot' to react in line with the assigned strain (Schramm, 2000). It is known that curves of the two moduli cross-over at a particular value of the angular frequency which is characteristic for the given polymer structure. Generally, when mean molecular weight of polymers increases, the crossing point of the $G^{\prime}(\omega)$ and $G^{\prime \prime}(\omega)$ curves is shifted to the lower frequencies. Simultaneously, a decrease of molecular weight distribution moves this point to higher values of moduli (Schramm, 2000). This means that samples with MM and - to a lesser extent with GOx, show properties which are characteristic for solutions of polymers with higher molecular weight. This may suggest that addition of NPs of montmorillonite or graphene oxide enhances mutual interactions between mucin molecules, increasing the crosslink density. Montmorillonite NPs probably interact with protein backbone whereas graphene oxide NPs - with side chains of mucin. This is not the case for BT NPs, since no crossing of $G^{\prime}(\omega)$ and $G^{\prime \prime}(\omega)$ is observed. In fact, these relationships are almost indistinguishable from pure MUC solutions. It must be stressed that results shown in Fig. 3 were obtained for extremely concentrated MUC solution where mutual interactions between mucin 

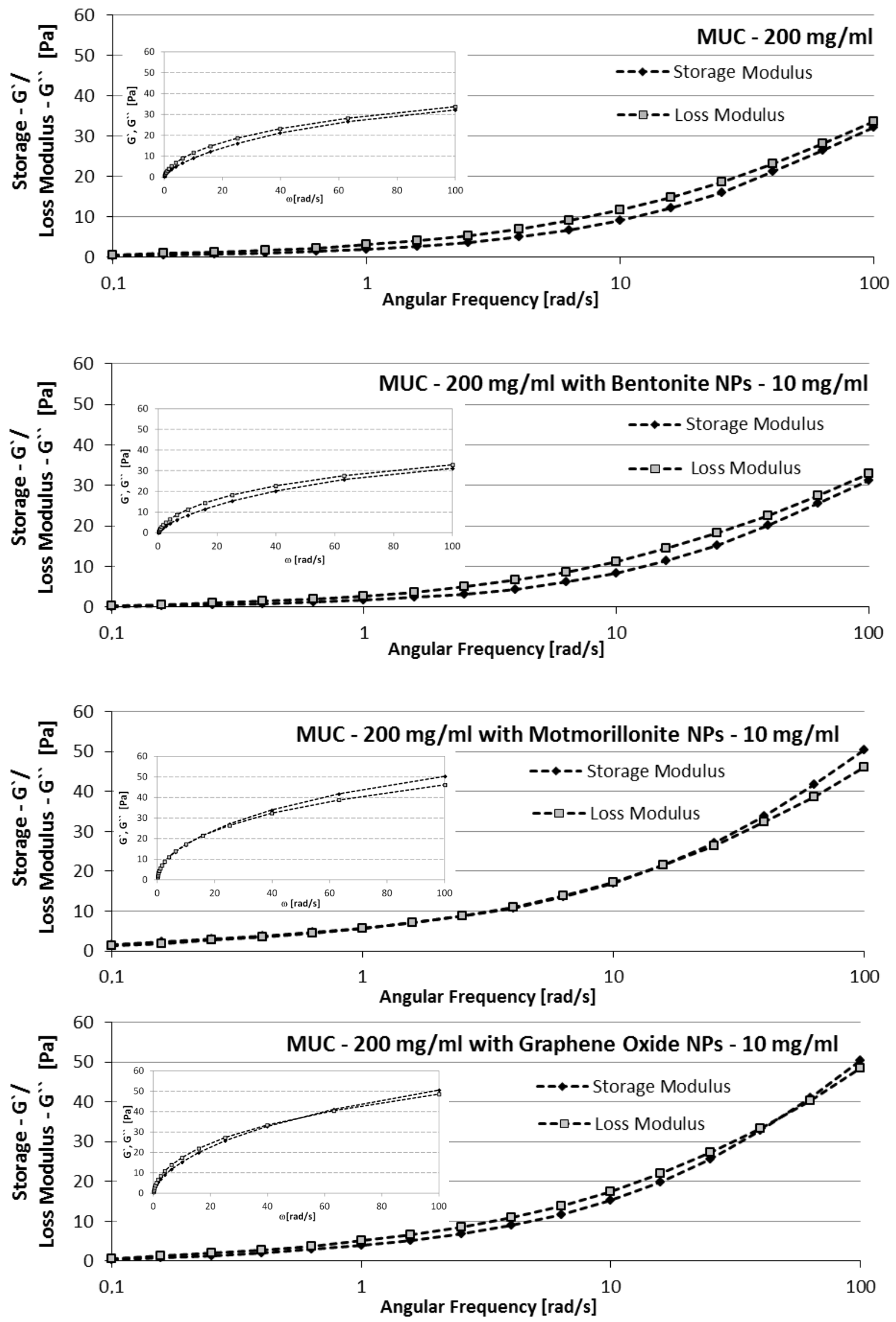

Fig. 2. Storage and loss moduli of $200 \mathrm{mg} / \mathrm{ml} \mathrm{MUC} \mathrm{and} \mathrm{MUC+NPs} \mathrm{samples} \mathrm{(strain} \mathrm{amplitude} \mathrm{3 \% ).} \mathrm{Inserts} \mathrm{show}$ the same relationships with linear scale of the frequency 


\section{MUC - $200 \mathrm{mg} / \mathrm{ml}$ with NPs - $10 \mathrm{mg} / \mathrm{ml}$}

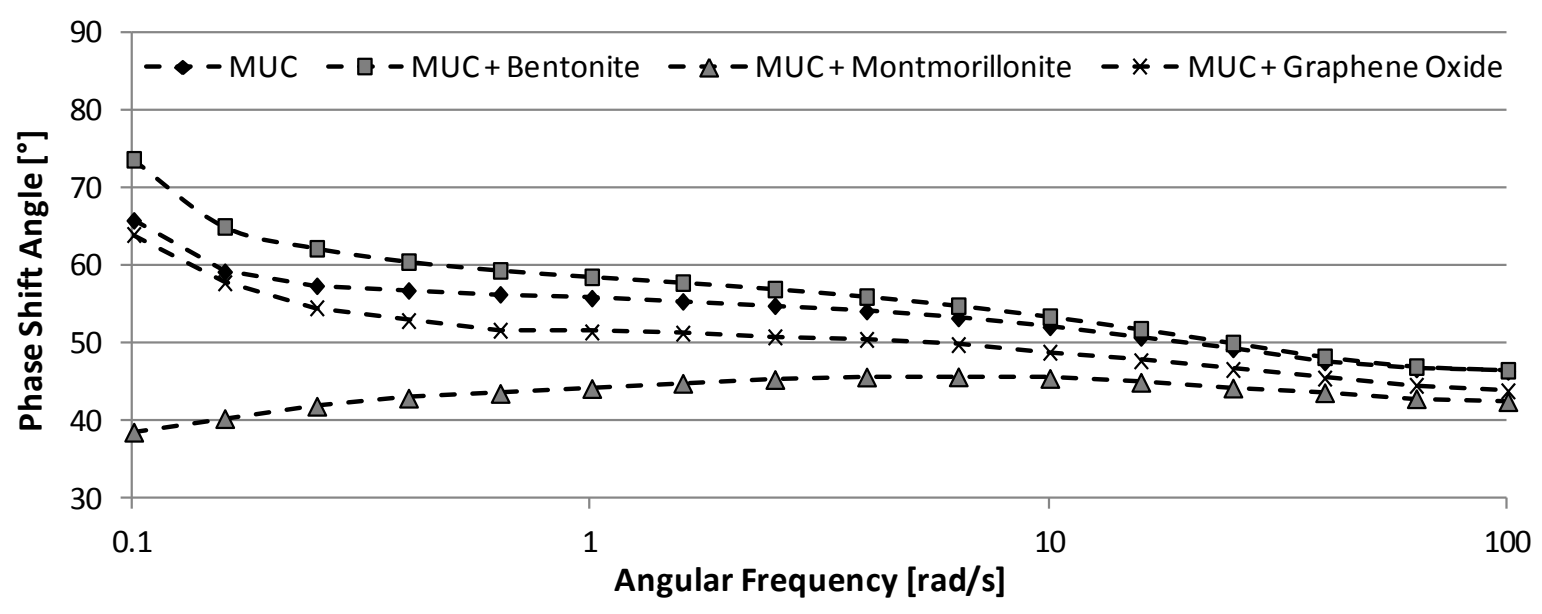

Fig. 3. Phase shift angle for $200 \mathrm{mg} / \mathrm{ml}$ MUC samples for strain amplitude 3\%

molecules were originally strong. Therefore, addition of NPs may modify these interactions only if particles have special properties. Hydrophobized MM probably forms aggregates in the aqueous phase which can stiffen the internal structure of MUC solution, and this explains the increase of both $G^{\prime}$ and $G^{\prime \prime}$. On the contrary, GOx is hydrophilic but has very high surface area $\left(\sim 150 \mathrm{~m}^{2} / \mathrm{g}\right.$ - Stobinski et al., 2014), which allows effective binding to polar moieties of MUC molecules, increasing the crosslinking interactions. BT, which is also hydrophilic, does not have such a large surface area $\left(\sim 67 \mathrm{~m}^{2} / \mathrm{g}\right.$ - Kondej and Sosnowski, 2013) so cannot bind to MUC so efficiently. In case of samples with pure mucin and mucin with bentonite NPs, the viscous response suppresses the elastic one in the whole range of angular frequencies. One of the possible explanations is polydispersion of mucin in the solution, which may be considered as a blend containing both very high- and very low-molecular weight molecules. Small molecules may act as a kind of low viscosity lubricants for the rest of the polymer while larger molecules may show up as an additional elasticity parameter (Schramm, 2000).

Figure 4 shows rheometric results obtained for $50 \mathrm{mg} / \mathrm{ml} \mathrm{MUC} \mathrm{with} \mathrm{tested} \mathrm{NPs}(1 \mathrm{mg} / \mathrm{ml})$. The values of both moduli were much lower than those for samples with higher mucin concentration. Moreover, the results show that only samples with MM and GOx were visco-elastic, and in this case elastic reaction on stress exceeded viscous reaction. In solution of pure mucin and in solution with addition of bentonite NPs storage modulus $\left(G^{\prime}\right)$ is close to 0 in all range of angular frequencies, so the liquid is purely viscous. The values of phase shift angles for those solutions are shown in Fig. 5. They confirm that elastic effects in both $50 \mathrm{mg} / \mathrm{ml} \mathrm{MUC} \mathrm{solution} \mathrm{and} \mathrm{in} \mathrm{this} \mathrm{solution} \mathrm{with} \mathrm{BT} \mathrm{can} \mathrm{be} \mathrm{detected} \mathrm{only}$ for very low angular frequencies $(\omega<10-15 \mathrm{rad} / \mathrm{s})$. On the contrary, MUC solutions with MM and GOx are visco-elastic in full range of angular frequencies, although the dissipative (viscous) part becomes dominant for higher values of $\omega$.

Results of mass transport experiments in all samples obtained for DC as a diffusing solute are shown in Fig. 6. It is evident that permeability of the layers of more concentrated MUC solutions is lower, independently of NP presence. In analogy to variations of rheological properties (Fig. 4), MM and GOx reduce the permeability of the layer of $200 \mathrm{mg} / \mathrm{ml}$ mucin solutions. $D_{\text {eff }}$ calculated for samples with MM and GOx $\left(D_{\text {eff }} \approx 2.6 \times 10^{-10} \mathrm{~m}^{2} / \mathrm{s}\right)$ is more than $10 \%$ lower than that of the control sample (pure mucin, $D_{\text {eff }}=2.95 \times 10^{-10} \mathrm{~m}^{2} / \mathrm{s}$ ). No effect on mass transfer rate was found for BT particles.

For samples with low mucin concentration $(50 \mathrm{mg} / \mathrm{ml}), D_{\text {eff }}$ in a control sample is relatively high $\left(\sim 4.5 \times 10^{-10} \mathrm{~m}^{2} / \mathrm{s}\right)$ and always decreases when any NPs are present. The strongest effect is observed for GOx where $D_{\text {eff }}$ is reduced by almost $35 \%$. In case of BT and MM particles, mass transfer hindrance is smaller and quite similar (by 10 and $15 \%$, respectively), although rheometric parameters obtained for 
these systems are significantly different. It confirms the observation that overall rheological properties of the complex fluid only partially can explain mass transfer phenomena, and material-dependent molecular interactions are also of relevance.
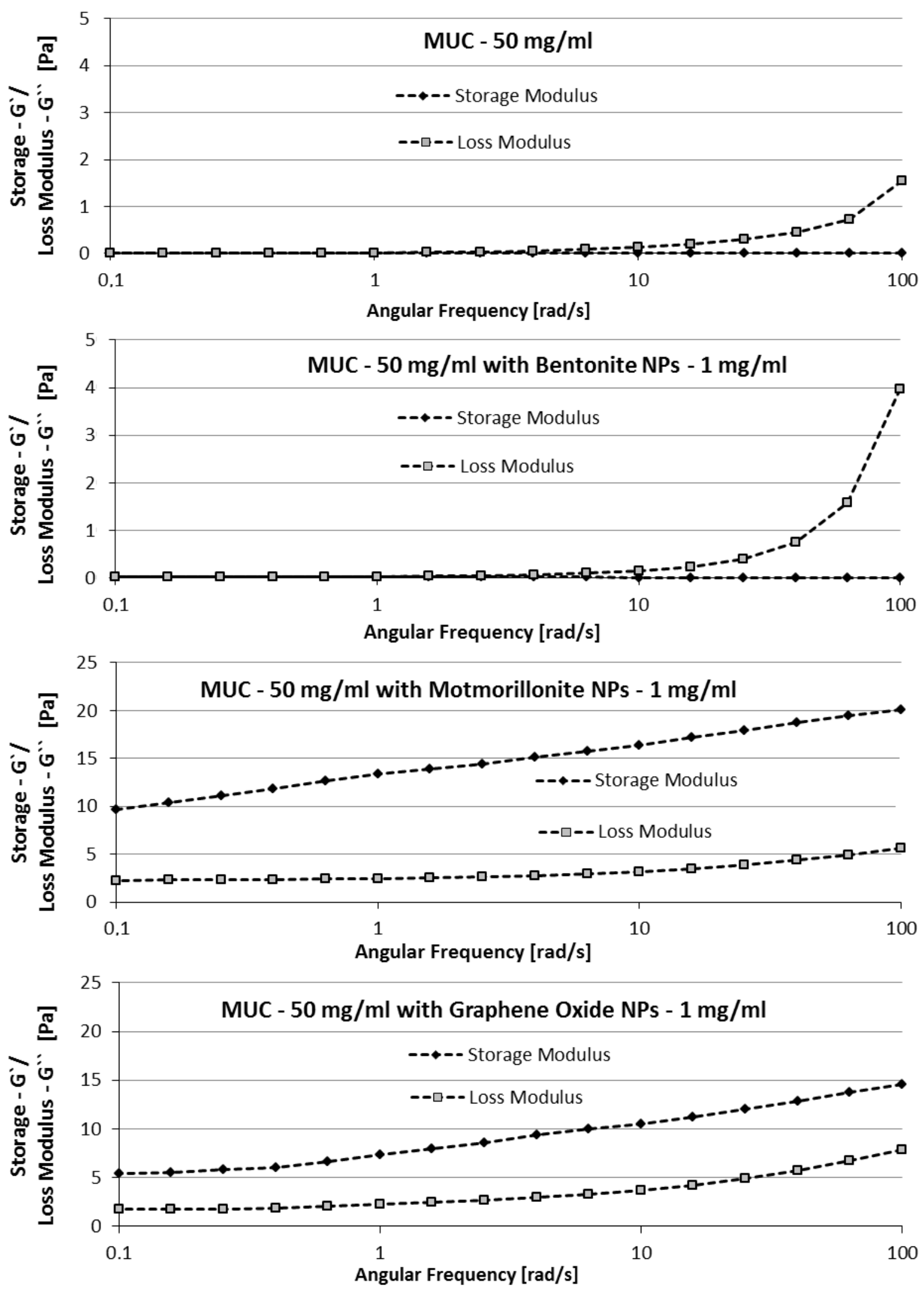

Fig. 4. Storage and loss moduli of $50 \mathrm{mg} / \mathrm{ml}$ MUC and MUC/NPs samples (strain amplitude 3\%) 
MUC - $50 \mathrm{mg} / \mathrm{ml}$ with NPs $-1 \mathrm{mg} / \mathrm{ml}$

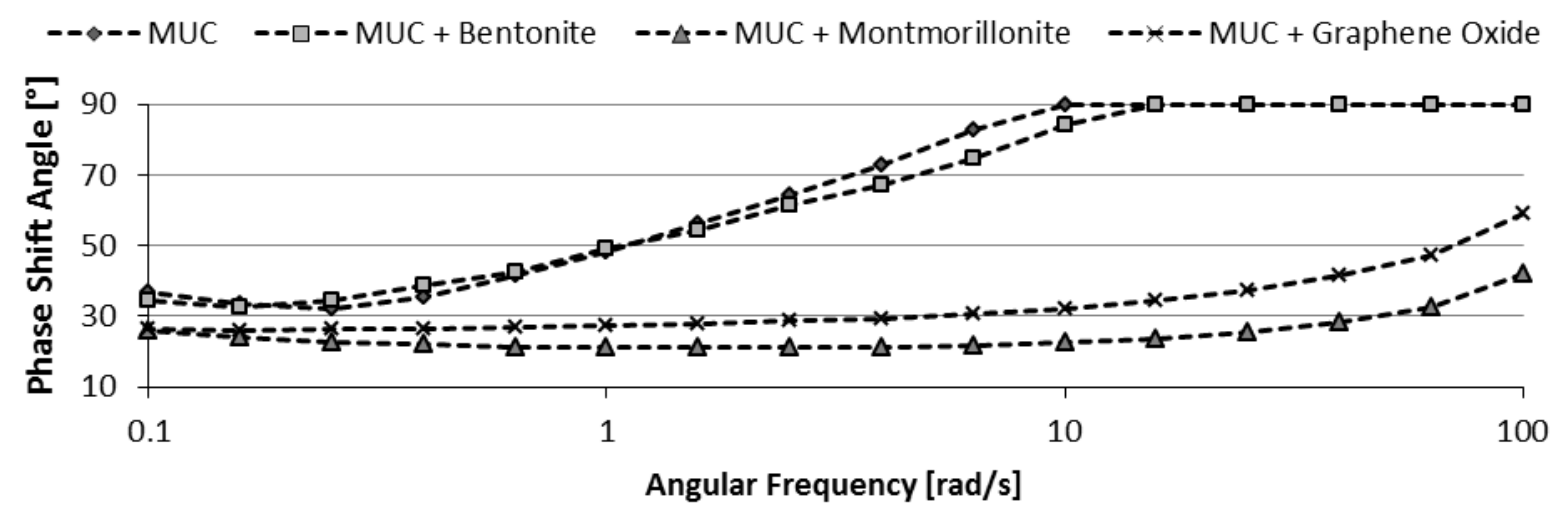

Fig. 5. Phase shift angle for $50 \mathrm{mg} / \mathrm{ml} \mathrm{MUC} \mathrm{samples} \mathrm{for} \mathrm{strain} \mathrm{amplitude} \mathrm{3 \%}$

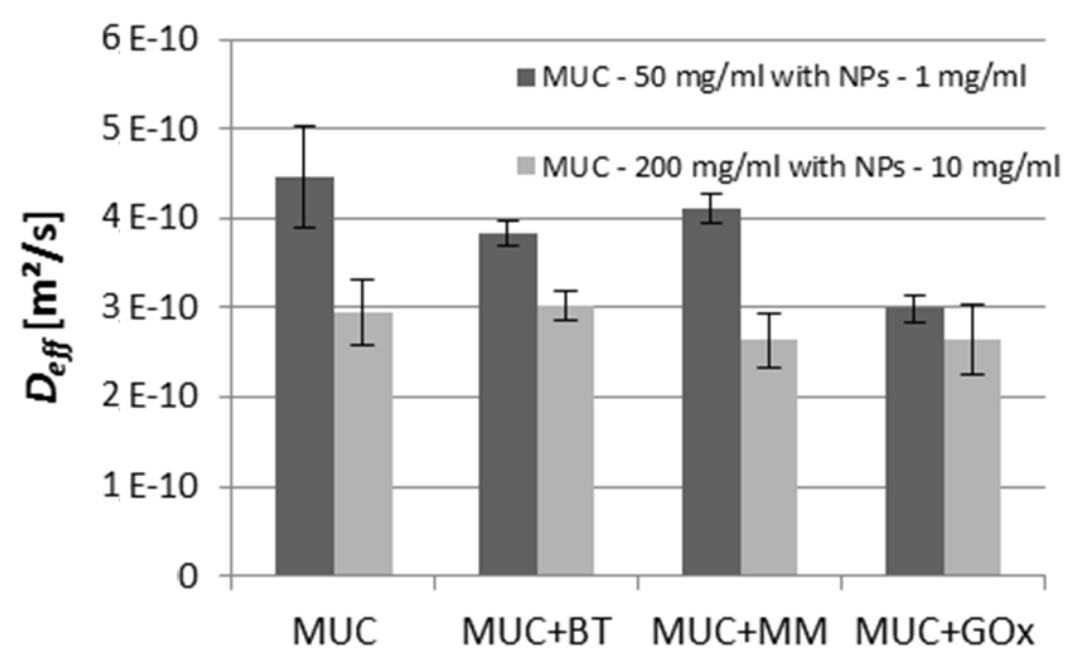

Fig. 6. The effective diffusion coefficient, $D_{\text {eff }}$ of DC in examined samples.

Average $\pm \mathrm{SD}$, number of replicates $=3$

\section{CONCLUSIONS}

Two-stage research reported in this paper confirms that transport properties of bronchial mucus are influenced by many interfering factors. In Part I it was shown that the peculiar chemical composition determines inter-molecular interactions in this complex liquid, which are reflected by variable rheological and permeability characteristics. Each of the essential mucus components (mucin, DNA, proteins) has its own input to the mass transfer resistance for solutes permeating through the mucus layer. Cooperative interactions of the mucus constituents allow to form a complex gel-like visco-elastic barrier which plays an essential role in the respiratory system. It is important for organism protection against inhaled pollutants. On the other hand, this barrier must be overcome by drugs delivered via inhalation, and this can be achieved by applying special drug carriers (Odziomek et al., 2012).

Part II of this study was focused on the properties of this protective layer in presence of nanostructured particles arriving to the mucus with inhaled contaminated air. The results confirmed that most of such particles increase visco-elastic properties of the mucus. This effect should be considred undesirable since it can lessen the rate of mucociliary clearance in vivo, so particles may remain for longer time and accumulate in the bronchial tree. Increased particle retention may be dangerous for health, especially if NPs carry toxic chemicals (such as carcinogenic volatile organics in case of combustion particles) 
which will have a longer time for washing-out from particulate carriers. Mucus accumulation in the airways also induces increased airway resistance and susceptibility to infection or inflammation, all being potentially dangerous for health. As shown by results of thes studies, drug penetration through a modified mucus layer may be noticeably slowed down, which calls for new strategies in medical treatment using inhaled drugs.

This work was supported by National Science Centre, projects No. 2011/03/N/ST8/04912 and 2014/13/ST8/00808.

\section{SYMBOLS}

$D_{\text {eff }} \quad$ effective diffusion coefficient in a stagnant liquid layer, $\mathrm{m}^{2} / \mathrm{s}$

$G^{\prime} \quad$ storage modulus, $\mathrm{Pa}$

$G^{\prime \prime} \quad$ loss modulus, $\mathrm{Pa}$

Greek symbols

$\phi \quad$ phase shift angle: $\phi=\arctan \left(G^{\prime \prime} / G^{\prime}\right)$

$\mu_{\mathrm{a}} \quad$ apparent viscosity (measured at constant shear rate), $\mathrm{Pa} \mathrm{s}$

$\omega \quad$ angular frequency range of strain, $\mathrm{rad} / \mathrm{s}$

\section{Abbreviations}

$\begin{array}{ll}A L B & \text { albumin } \\ B T & \text { bentonite (nanoclay) } \\ C A & \text { carminic acid } \\ D C & \text { disodium cromoglycate } \\ D N A & \text { deoxyribonucleic acid } \\ H D C & \text { horizontal diffusion cell } \\ G O x & \text { graphene oxide } \\ H P L C & \text { high performance liquid chromatography } \\ M I X & \text { mixed system: MUC + DNA + ALB } \\ M M & \text { hydrophobic montmorillonite (nanoclay) } \\ M U C & \text { mucin } \\ N A C & \text { N-acetylcysteine } \\ N P & \text { nanostructured particle } \\ P T S & \text { mucin domains with high content of proline, threonine, and serine } \\ S D & \text { standard deviation }\end{array}$

\section{REFERENCES}

Bansil R., Turner B. S., 2006. Mucin structure, aggregation, physiological functions and biomedical applications. Curr. Opin. Colloid Interface Sci., 11, 164-170. DOI: 10.1016/ j.cocis.2005.11.001.

Bhat P. G., Flanagan D. R., Donovan M. D., 1995. The limiting role of mucus in drug absorption: drug permeation through mucus solution. Int. J. Pharm., 126, 179-187. DOI: 10.1016/0378-5173(95)04120-6.

Brodin B., Steffansen B., Nielsen C. U., 2010. Molecular biopharmaceutics. Pharmaceutical Press, London.

Cone R. A., 2009. Barrier properties of mucus. Adv. Drug Deliv. Rev., 61, 75-85. DOI: 10.1016/j.addr.2008.09.008. 
Desai M. A., Vadgama P., 1992. Estimation of effective diffusion coefficients of model solutes through gastric mucus: assessment of a diffusion chamber technique based on spectrophotometric analysis. Analyst, 116, 11131116. DOI: $10.1039 /$ AN9911601113.

King M., 2005. Physiologic basis of respiratory disease. BC Decker Inc., Hamilton, 409-416.

Kondej D., Sosnowski T. R., 2013. Alteration of biophysical activity of pulmonary surfactant by aluminosilicate nanoparticles. Inhal. Toxicol., 25, 77-83. DOI: 10.3109/08958378.2012. 756087.

Lai S. K., Wang Y., Wirtz D., Hanes J., 2009. Micro- and macrorheology of mucus. Adv. Drug Deliv. Rev., 61, 86-100. DOI:10.1016/j.addr.2008.09.012.

Muhr A. H., Blanshard J. M. V., 1982. Diffusion in gels. Polymer, 23, 1012-1026. DOI: 10.1016/00323861(82)90402-5.

Marijnissen J., Gradoń L. (Eds.), 2010. Nanoparticles in medicine and environment. Inhalation and health effects. Springer, Dordrecht.

Norris D. A., Sinko P. J., 1997. Effect of size, surface charge, and hydrophobicity on the translocation of polystyrene microspheres through gastrointestinal mucin. J Appl. Polym. Sci. 63, 1481-1492. DOI: 10.1002/(SICI)1097-4628(19970314)63.

Oberdörster G., 1995. Lung particle overload: implications for occupational exposures to particles. Regul. Toxicol. Pharmacol., 21, 123-135. DOI: 10.1006/rtph.1995.1017.

Odziomek M., Sosnowski T. R., Gradoń L., 2012. Conception, preparation and properties of functional carrier particles for pulmonary drug delivery. Int. J. Pharm., 433, 51-59. DOI: 10.1016/j.ijpharm.2012.04.067.

Odziomek M., Sosnowski T. R., Gradoń L., 2015. The Influence of Functional Carrier Particles (FCPs) on the molecular transport rate through the reconstructed bronchial mucus: In vitro studies. Transp. Porous Media, 106, 439-454. DOI: 10.1007/s11242-014-0409-1.

Rohs R., Jin X., West S. M., Joshi R., Honig B., Mann R. S., 2010. Origins of specificity in protein-DNA recognition. Annu. Rev. Biochem., 79, 233-269. DOI: 10.1146/annurev-biochem -060408-091030.

Rubin B. K., 2009. Mucus, phlegm, and sputum in cystic fibrosis. Respir. Care. 54, 726-732.

Sanders N. N., De Smedt S. C., Van Rompaey E., Simoens P., De Baets F., Demeester J., 2000. Cystic fibrosis sputum: a barrier to the transport of nanospheres. Am. J. Respir. Crit. Care Med., 162, 1905-11. DOI: 10.1164/ajrccm.162.5.9909009.

Schramm G., 2000. A practical approach to rheology and rheometry. $2^{\text {nd }}$ edition, Gebrueded HAAKE GmbH, Karlsruhe.

Sosnowski T.R., 2015. Nanosized and nanostructured particles in pulmonary drug delivery. J. Nanosci. Nanotechnol. 15, 3476-3487. DOI: 10.1166/jnn.2015.9863.

Sosnowski TR., Koliński M., Gradoń L., 2011. Interactions of benzo[a]pyrene and diesel exhaust particulate matter with the lung surfactant system. Ann. Occup. Hyg., 55, 329-338. DOI: 10.1093/annhyg/mer007.

Stobinski L., Lesiak B., Malolepszy A. Mazurkiewicz M., Mierzwa B., Zemek J., Jiricek P. Bieloshapka I., 2014. Graphene oxide and reduced graphene oxide studied by the XRD, TEM and electron spectroscopy methods. J. Electron. Spectrosc. Relat. Phenom., 195, 145-154. DOI: 10.1016/j.elspec.2014.07.003.

Truskey G., Yuan F., Katz D., 2009. Transport phenomena in biological system. $2^{\text {nd }}$ edition, Pearson Prenticee Hall.

Widdicombe J. G., 1997. Airway liquid: A barrier to drug diffusion? Eur. Respir. J., 10, $2194-2197$. DOI: $10.1183 / 09031936.97 .10102194$.

Woodley J., 2001. Bioadhesion: New possibilities for drug administration? Clin. Pharmacokinet., 40, 77-84. DOI: 10.2165/00003088-200140020-00001.

Yang W., Peters J. I., Williams R. O., 2008. Inhaled nanoparticles-a current review. Int. J. Pharm., 356, $239-47$. DOI: 10.1016/j.ijpharm.2008.02.011.

Received 30 November 2016

Received in revised form 14 February 2017

Accepted 15 March 2017 